\title{
Analisa Waktu Operasi Terhadap Temperatur dan Tekanan pada Mesin Diesel
}

\author{
Nasmi Herlina Sari ${ }^{11^{*}}$, Suteja $^{2)}$, Yudi Ahmad Efendi ${ }^{3)}$ \\ ${ }^{1,2,3)}$ Jurusan Teknik Mesin Fakultas Teknik Universitas Mataram, Jalan Majapahit No. 62 Mataram \\ Email: n.herlinasari@unram.ac.id; suteja.eng@gmail.com; ahmadefendiyudi@gmail.com
}

doi: https://doi.org/10.24843/METTEK.2021.v07.i01.p05

\begin{abstract}
Abstrak
Studi ini bertujuan untuk menganalisa temperatur, dan tekanan pada setiap komponen mesin diesel Sulzer 16 ZAV 40S selama beroperasi 8 jam. Penelitian ini dilakukan di PT. Iradat Aman Sektor Pringga baya Lombok. Engine Control Panel (ECP) dan Generator Control Panel (GCP) telah digunakan untuk menentukan nilai dari tekanan, dan temperatur berdasarkan sensor yang telah dipasang pada komponen mesin. Pengukuran temperatur dan tekanan dilakukan setiap jam selama 8 jam. Hasil penelitian menunjukkan bahwa setelah mesin beroperasi selama 4 jam sampai $7 \mathrm{jam}$; temperatur stator, temperatur gas buang, temperature silinder sisi A dan silider sisi B mengalami penurunan yang signifikan dikarenakan kebocoran pada silinder A dan B. Sedangkan tekanan pada mesin masih normal dan tidak mengalami perubahan yang signifikan.
\end{abstract}

Kata kunci: temperatur, mesin diesel, tekanan, waktu beroperasi.

\begin{abstract}
This study aims to analyze the temperature and pressure of each component of the Sulzer 16 ZAV $40 S$ diesel engine for 8 hours of operation. This research was conducted at PT. Iradat Aman Sector Pringga Baya Lombok. The Engine Control Panel (ECP) and Generator Control Panel (GCP) have been used to determine the value of pressure and temperature based on sensors that have been installed on engine components. Temperature and pressure measurements were carried out every hour for 8 hours. The results showed that after the machine operated for 4 hours to 7 hours; stator temperature, exhaust gas temperature, cylinder temperature side $A$ and side cylinder $B$ experienced a significant decrease due to leaks in cylinders $A$ and $B$. On the other hand, the pressure on the engine was still normal and did not experience a significant change.
\end{abstract}

Keywords: temperature, diesel engine, pressure, operating time.

\section{PENDAHULUAN}

Pembakaran sejumlah bahan bakar tertentu dimaksudkan untuk menghasilkan daya dan menggerakkan motor bakar. Proses pembakaran juga memiliki efek samping seperti getaran mesin dan bunyi akibat adanya gesekan. Untuk jenis mesin tertentu, diesel, bunyi dan getaran yang dihasilkan sangat besar sehingga mengurangi kenyamanan pemakai, sekaligus dapat menimbulkan gangguan kesehatan jika terjadi terus menerus dalam jangka waktu yang cukup lama.

Beberapa peneliti terdahulu telah melaporkan penyelidikan terkait dengan efek dari getaran, bunyi atau kebisingan pada system kerja mesin. Sadiana [1] menyatakan bahwa getaran merupakan suatu fenomena yang tidak bisa dihindari dari suatu sistem kerja mesin.

Penulis korespondensi,

Email: n.herlinasari@unram.ac.id 
Laksono [2] telah menganalisa ruang kamar mesin pada kapal penyeberangan ketapanggilimanuk KMP Dharma Rucitra. Ia menyatakan bahwa getaran terjadi akibat dari transfer gaya siklik melalui elemen-elemen pada mesin yang ada, dimana elemen tersebut saling bereaksi antara satu dengan yang lainnya dan energi didesipasi melalui struktur dalam bentuk getaran. Sedangkan, Kurnia dkk.,[3] telah menyatakan bahwa tingkat kebisingan akibat kegiatan transportasi di jalan Sisingamangaraja, dan Meulaboh Aceh Barat asih di atas baku mutu (> 55 dBA). Kemudian, Nasution, [4] telah melaporkan nilai ambang kebisingan di atas $80 \mathrm{~dB}$ berpengaruh pada efisiensi kerja dan produksi. Selain getaran parameter lain yang mempengaruhi mesin yaitu temperatur, tekanan, bahan bakar, dan udara [5].

Mesin diesel termasuk salah satu jenis motor pembakaran dalam yang juga biasa disebut compressed ignition, penyalaan bahan bakar secara spontan karena bahan bakar diinjeksikan ke dalam silinder yang berisi udara dan tekanan yang tinggi [5]. Campuran udara dan bahan bakar yang bertekanan tinggi akan menyebabkan temperatur menjadi tinggi, sehingga proses penyalaan pada saat proses pembakaran menjadi lebih mudah [6]. Proses pembakaran akan terganggu jika temperatur terlalu tinggi akibat terganggunya pendinginan maka berpengaruh pada proses pembakaran. Sumardiyanto dan Susilowati, [7] melaporkan bahwa penurunan kualitas udara pembakaran dipengaruhi oleh pendingin udara yang tidak optimal dan terganggunya saluran udara karena kotoran pada filter.

Kualitas pembakaran dapat dijaga dengan menggunakan pemanas bahan bakar sehingga viskositas bahan bakar dapat disesuaikan. Dharma dkk., [8] telah menggunakan dua bahan bakar yaitu MFO dan HSD di PLTD sektor pringga baya. Sebelum bahan bakar MFO memasuki ruang bakar, akan dipanaskan terlebih dahulu sehingga viskositas MFO sama dengan viskositas HSD. Ia menemukan bahwa naiknya viskositas bahan bakar menyebabkan pengkabutan dan pencampuran bahan bakar dengan udara menjadi lebih homogen sehingga pembakaran lebih sempurna. Indartono dan Murni, [9] melaporkan bahwa pemakaian alat pemanas bahan bakar dapat menurunkan konsumsi bahan bakar rata-rata sebesar 8,22\% bila dibandingkan dengan tanpa pemakaian alat pemanas bahan bakar. Dari karya-karya ini menunjukkan bahwa penyelidikan terhadap efek waktu operasi terhadap mesin diesel belum pernah diinvestigasi. Padahal sangat lama waktu beroperasi sebuah mesin diesel akan mempengaruhi kinerja dari mesin itu sendiri.

Oleh karena itu, studi ini bertujuan untuk menganalisa temperatur, dan tekanan terhadap komponen pada Mesin Diesel Sulzer Type 16 ZAV 40S. Studi kasus ini dilakukan di pembangkit Listrik Tenaga Diesel PT. Iradat Aman Sektor Pringga Baya. Hasil studi ini dapat digunakan sebagai informasi bagi industri untuk menjaga kualitas pembakaran.

\section{METODE}

\subsection{Pengukuran temperatur dan tekanan}

Penelitian telah dilakukan pada Pembangkit Listrik Tenaga Diesel (PLTD) cabang Pringgabaya. Engine Control Panel (ECP) dan Generator Control Panel (GCP) (lihat gambar 1a dan 1 b) telah digunakan untuk menentukan nilai dari tekanan, dan temperatur berdasarkan sensor yang telah dipasang pada beberapa bagian atau komponen mesin, sensor akan mengirimkan sinyal ke panel yang diterjemahkan ke dalam bentuk angka. Panel mesin membaca temperatur, tekanan, dan kecepatan putaran turbo (Turbo A dan B). Lebih lanjut, panel generator membaca beban dan daya yang dihasilkan dalam setiap jamnya. Data diperoleh dengan cara menekan tombol dan menarik analog pada panel. Sedangkan, untuk mengukur getaran masih menggunakan manual, yaitu dengan cara membandingkan getaran pada cylinder head yang baru dipasang atau getarannya masih halus. Pengambilan data dilakukan setiap jam mulai dari jam 9 pagi sampai jam 4 sore dan dari jam 5 sampai jam 6 pagi, data kemudian dicatat di lembaran log sheet control room. 


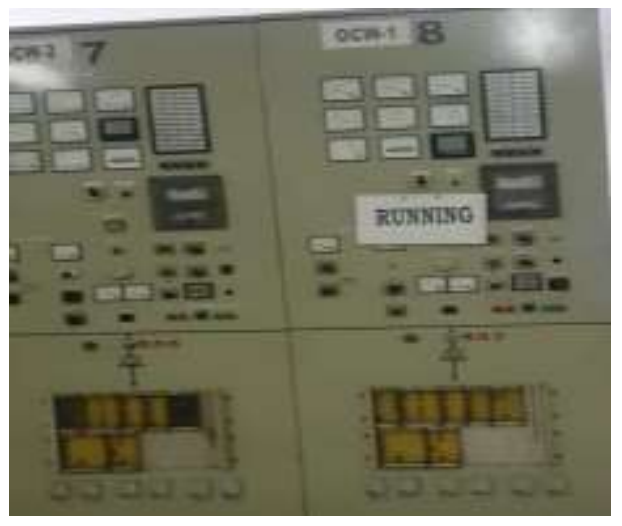

(a)

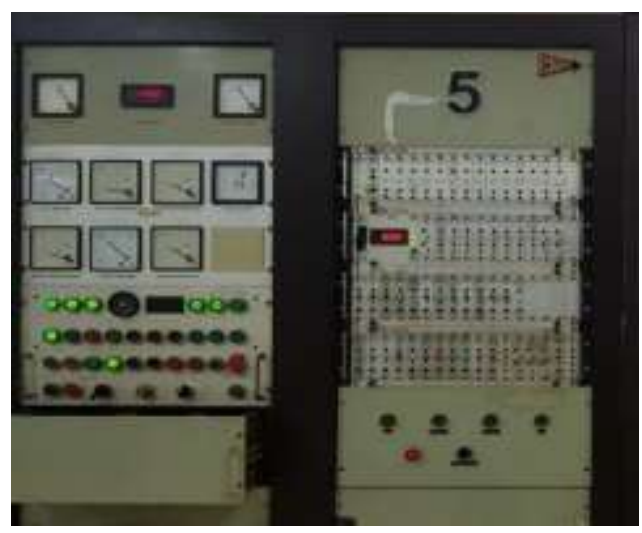

(b)

Gambar 1. (a) Generator Control Panel, dan (b) Engine Control Panel

\subsection{Menentukan batas komponen temperatur dan tekanan}

Tabel 1 menunjukkan sebuah log sheet dan proses pengambilan data dalam setiap jamnya selama 8 jam. Dari tabel 1 juga menunjukkan data standar temperatur dan tekanan, dimana data yang diambil tidak melebihi atau kurang dari standar, dan jika data yang diperoleh kurang dari standar maka alarm trip akan berbunyi dan jika melebihi standar maka mesin mati secara otomatis.

Tabel 1 Batas temperatur dan tekanan

\begin{tabular}{|c|c|c|c|}
\hline Komponen & $\begin{array}{c}\text { Batas } \\
\text { (maksimum/minimum) }\end{array}$ & Satuan & $\begin{array}{c}\text { Jumlah } \\
\text { (unit) }\end{array}$ \\
\hline $\begin{array}{l}\text { Temperatur gas buang silinder sisi } \\
\text { A }\end{array}$ & Alarm $=530:$ C Trip $=550: C$ & ${ }^{\circ} \mathrm{C}$ & 8 \\
\hline $\begin{array}{l}\text { Temperatur gas buang silinder sisi } \\
\text { B }\end{array}$ & Alarm $=120:$ C Trip $=130: C$ & ${ }^{\circ} \mathrm{C}$ & 8 \\
\hline Temperatur stator & Alarm $=88: C$ Trip $=93: C$ & ${ }^{\mathrm{o}} \mathrm{C}$ & 6 \\
\hline Temperatur bearing & Alarm $<12$ Bar & ${ }^{\circ} \mathrm{C}$ & 9 \\
\hline Starting Air Pressure & Alarm $<6$ Bar & Bar & 1 \\
\hline Instrument Air Pressure & Alarm $=2$ Bar, Trip $=1.5$ Bar & Bar & 1 \\
\hline Cyl CW Pressure & Alarm $=2$ Bar & Bar & 1 \\
\hline Injector Cooling Pressure & Alarm $=2$ Bar & Bar & 1 \\
\hline LT Water Pressure & Alarm $=4$ Bar, Trip $=3.5$ Bar & Bar & 1 \\
\hline Oil Pressure & Alarm $=5$ Bar, Trip 4 Bar & Bar & 1 \\
\hline Fuel Pressure & Alarm $<12$ Bar & Bar & 1 \\
\hline Cylinder CW Temperature & Alarm $=92: C$, Trip $=98: C$ & ${ }^{\circ} \mathrm{C}$ & 1 \\
\hline Injector Water Temperature & Alarm $=77: C$ & ${ }^{\circ} \mathrm{C}$ & 1 \\
\hline Lube Oil Temperature & Alarm $=60: \mathrm{C}$ & ${ }^{\circ} \mathrm{C}$ & 1 \\
\hline Fuel temperature/Viscosity & Alarm $=145: \mathrm{C} / 13-17 \mathrm{Cst}$ & ${ }^{\circ} \mathrm{C} / \mathrm{Cst}$ & 1 \\
\hline LT temperature & Alarm $=50: C$ & ${ }^{\circ} \mathrm{C}$ & 1 \\
\hline Alt. Bearing Temperature & Alarm $=88: C$, Trip $=93: C$ & ${ }^{\circ} \mathrm{C}$ & 1 \\
\hline
\end{tabular}




\section{HASIL DAN PEMBAHASAN}

\subsection{Analisa temperatur gas buang}

Gambar 2 menunjukkan data hasil pengukuran temperatur gas buang setiap jam menggunakan ECP maupun GCP. Dari gambar 2 menunjukkan bahwa temperatur gas buang selama 1 jam - 2 jam, tidak mengalami penurunan yang signifikan, namun setelah 3 jam, temperatur gas buang mengalami penurunan yang sangat jauh, sehingga beban mesin harus dikurangi agar tidak terjadi trip atau mati secara otomatis, dan setelah 4 jam berikutnya temperatur gas buang kembali normal.

Lebih lanjut, gambar 3 menunjukkan adanya penurunan temperatur gas buang setelah 1 jam hingga 3 jam, dan setelah 1 jam kemudian temperatur kembali normal dan turun kembali setelah 2 jam berikutnya. Kondisi ini terjadi berulang yang menunjukkan bahwa silinder kurang baik dan mengalami kebocoran sehingga mempengaruhi kinerja mesin. Agar performansi mesin baik maka perlu dilakukan penggantian silinder.

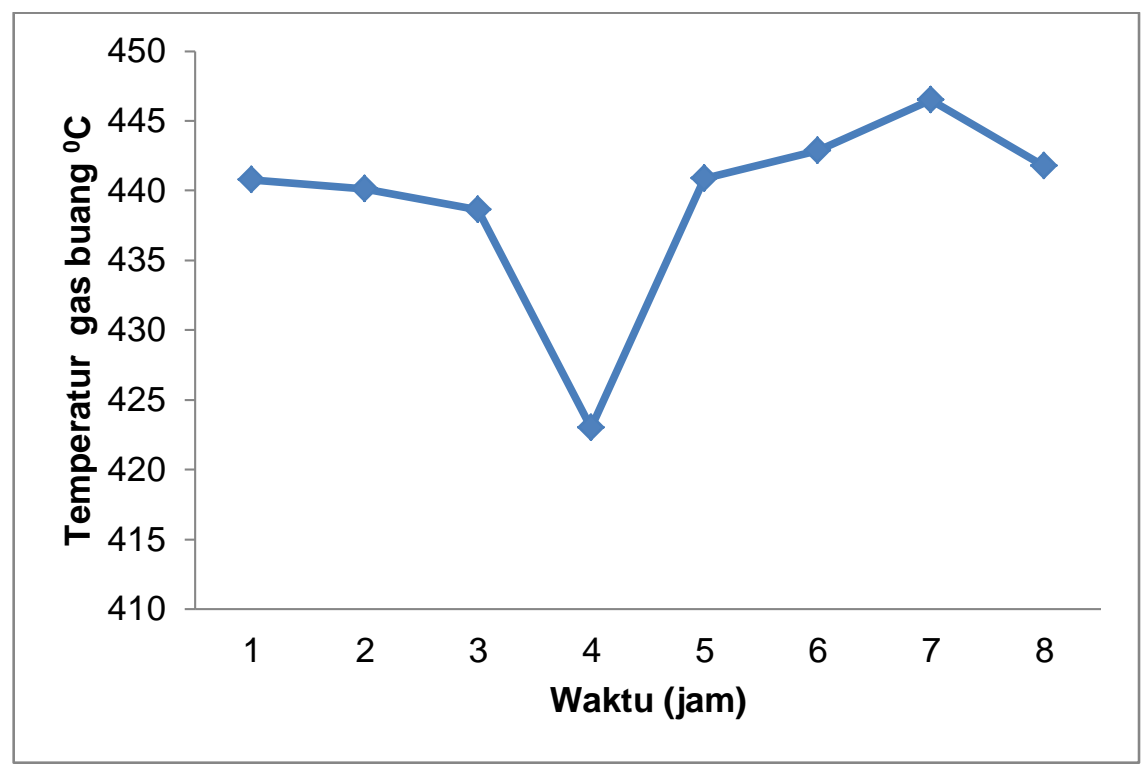

Gambar 2. Temperatur gas buang pada silinder sisi A waktu mesin Diesel Sulzer Type 16 ZAV $40 \mathrm{~S}$ beroperasi

Temperatur tinggi berkaitan dengan waktu pengoperasian dan pendingin semakin lama mesin beroperasi maka temperatur mengalami kenaikan dan diperlukan pendingin yang bisa mengimbanginya, seperti yang kita lihat pada gambar 3 setelah 4 jam beroperasi temperatur gas buang naik dan terus naik sampai 5 jam, hal ini terjadi karena lamanya mesin beroperasi akibatnya oli pada pendingin juga akan habis, akibatnya temperatur pada gas buang akan terus meningkat. Pada gambar 3 juga memperlihatkan temperatur gas buang tertinggi terjadi pada awal pengoperasian dikarenakan silinder sisi B memang membutuhkan temperatur yang tinggi disebabkan pada sisi B terjadi starting sehingga temperatur gas buangnya tinggi diawal proses pembakaran. 


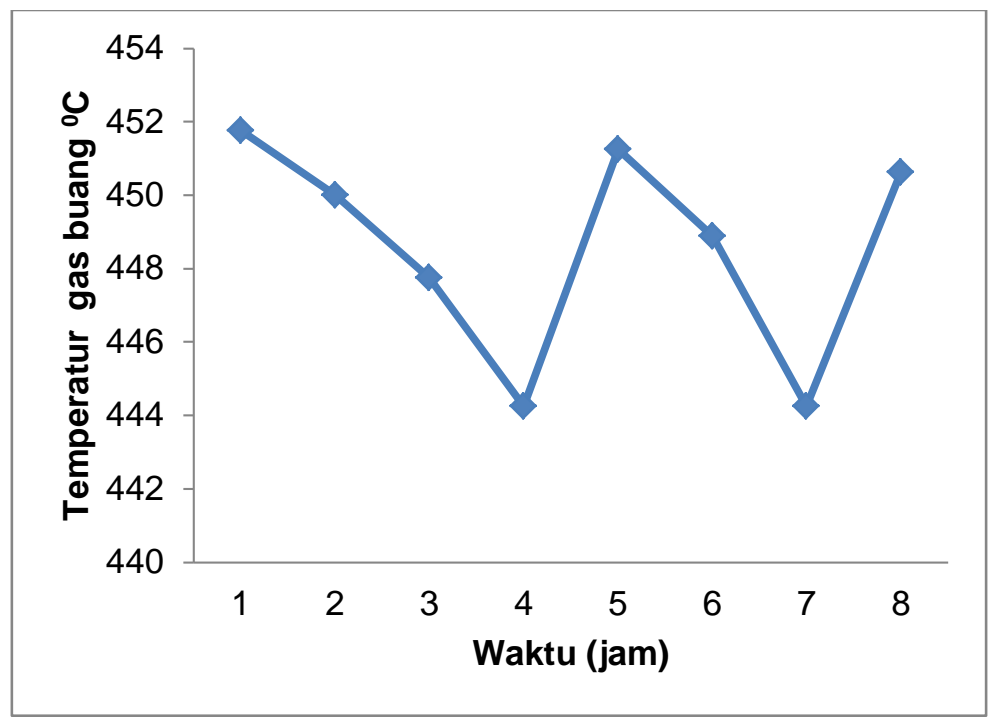

Gambar 3. Temperatur gas buang pada silinder sisi B terhadap waktu beroperasi Mesin Diesel Sulzer Type 16 ZAV 40S

Pada silinder sisi A dan silinder sisi $\mathrm{B}$, temperatur terendah terjadi setelah 4 jam beroperasi, dan pada 6 jam beroperasi, penurunan temperatur tersebut terjadi karena banyaknya udara yang masuk pada ruang bakar dimana udara berlebih maka pembakaran akan berkurang dan tidak sempurna.

\subsection{Analisa temperatur stator}

Gambar 4 menunjukkan bahwa temperature stator mengalami sedikit kenaikan dari waktu awal hingga setelah 3 jam beroperasi, namun setelah beroperasi selama 4 jam, temperatur stator mengalami penurunan drastis dan naik kembali setelah satu jam berikutnya hingga mencapai angka $800 \mathrm{C}$, ini menunjukkan temperatur stator masih dibawah temperatur maksimal dan aman.

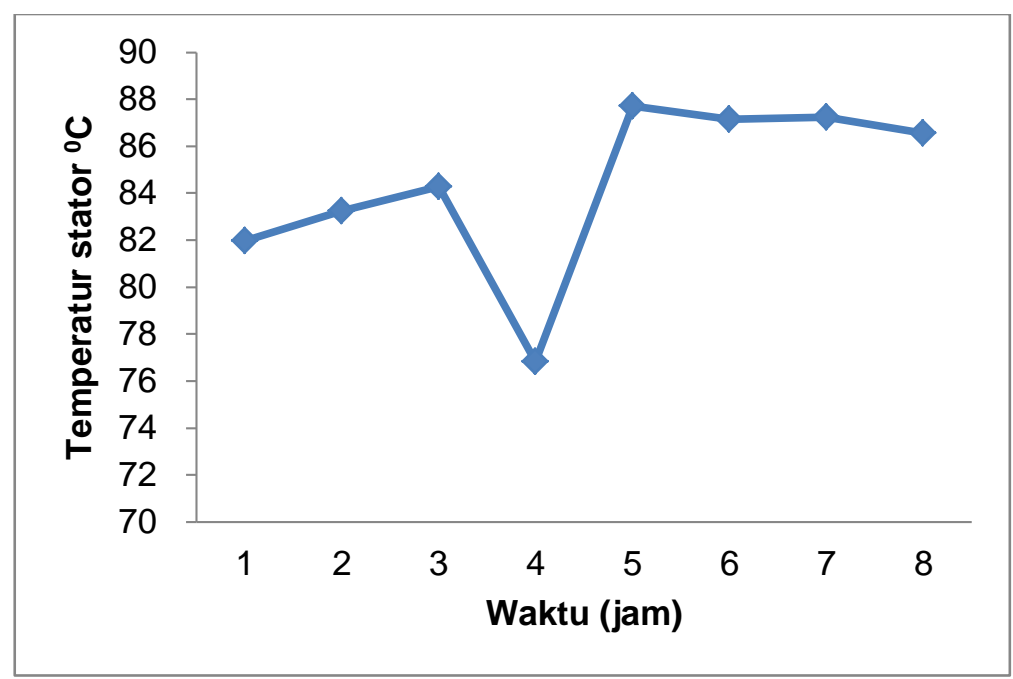

Gambar 4. Temperatur stator terhadap waktu beroperasi pada mesin Diesel Sulzer Type 16 ZAV $40 \mathrm{~S}$ 
Nasution [4], menyatakan bahwa jika temperature stator melebihi batas dapat menyebabkan gangguan pada generator stator hal ini disebabkan stator sebagai tempat untuk menerima induksi magnet dari rotor. Lebih lanjut, gambar 4 temperatur stator cenderung terus naik hal ini di indikasi generator berputar secara terus menerus sehingga menyebabkan kumparan stator menjadi semakin panas. Setelah 4 jam beroperasi, temperatur tertinggi pada stator ditemukan sebesar $88^{\circ} \mathrm{C}$ diduga akibat penurunan drastis temperatur stator setelah 4 jam beroperasi dan dinaikkannya beban sehingga temperature naik dengan cepat tetapi masih masih dalam kategori temperatur normal dan tidak mengganggu performa mesin.

\subsection{Analisa temperatur bearing}

Gambar 5 menyajikan temperatur bearing selama waktu beroperasi. Diketahui bahwa temperature bearing mengalami penurunan setelah beroperasi selama 4 jam, dan naik kembali setelah satu jam berikutnya. Pada kondisi ini temperatur bearing masih dikatakan aman karena temperatur masih di bawah $80{ }^{\circ} \mathrm{C}$. Tingginya temperatur pada bearing terjadi karena putaran yang terjadi secara terus menerus dan hanya mengalami penurunan drastis setelah 4 jam beroperasi. Jika temperatur terus meningkat dapat menyebabkan kehausan pada bearing, untuk mengantisipasi hal tersebut, mesin akan mati secara otomatis apabila temperatur sudah mencapai batas maksimal. Sedangkan, temperatur terendah ditemukan terjadi setelah mesin beroperasi selama 4 jam yang diduga terjadi adanya masalah pada ruang bakar sehingga mempengaruhi putaran bearing, yang menyebabkan putaran bearing akan semakin lambat akibatnya temperaturnya menurun.

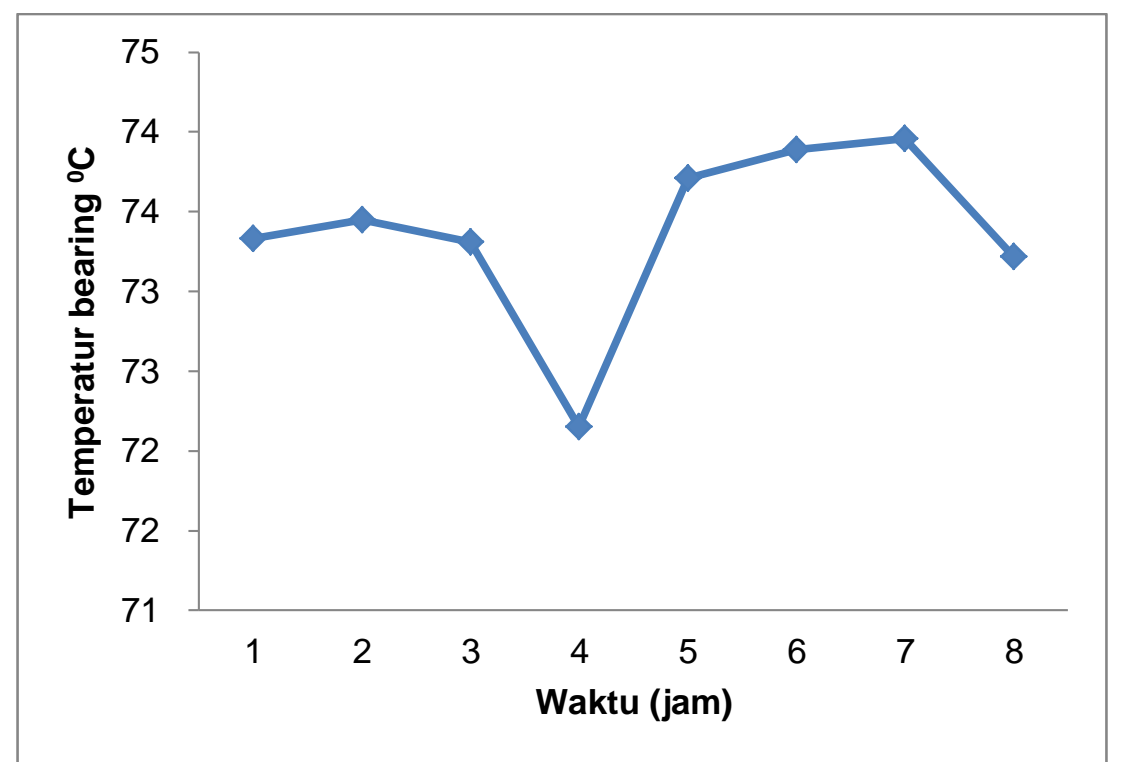

Gambar 5. Temperatur bearing terhadap waktu beroperasi mesin diesel Sulzer Type 16 ZAV $40 \mathrm{~S}$ 


\subsection{Analisa efek tekanan terhadap komponen mesin}

Gambar 6 menunjukkan tekanan yang dialami komponen mesin masih dikatakan aman karena angka yang ditunjukkan parameter tekanan tidak ada yang melebihi angka maksimum atau minimum yang telah ditentukan. Tekanan pada instrument air pressure nilainya 8 bar dengan batas minimum 6 bar, cylinder cooling water pressure 3.16 bar dengan batas maksimal 1.5 bar, injector cooling pressure 2.89 bar dengan batas minimum 2 bar, LT water pressure 2.62 dengan batas minimum 2 bar, lube oil pressure 4.65 bar dengan batas minimum 3.5 bar, dan fuel pressure 7.57 bar dengan batas minimum 4 bar.

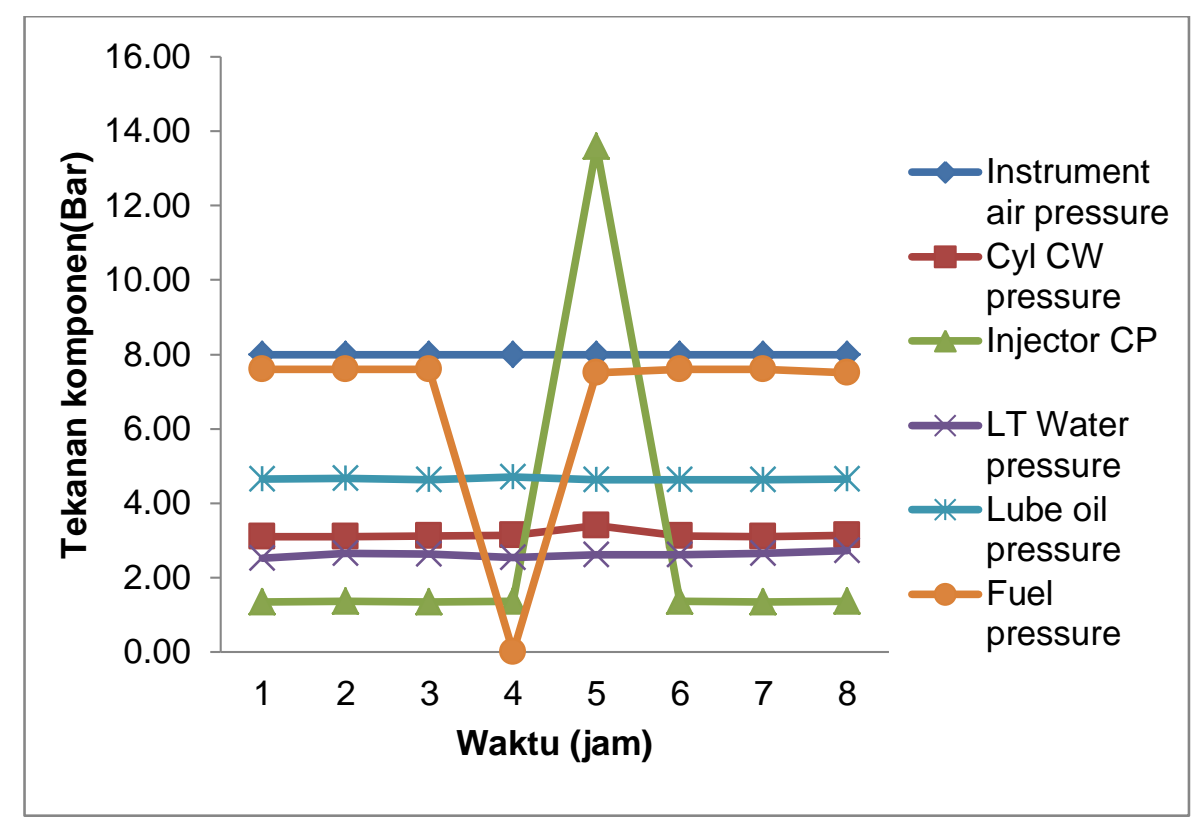

Gambar 6. Efek tekanan terhadap komponen mesin diesel Sulzer Type 16 ZAV 40S

Tekanan tertinggi yaitu pada instrument air pressure terjadi secara konstan, tekanannya harus dijaga tetap pada 8.0 bar apabila tekanan mengalami kenaikan atau penurunan, pihak operator akan segera menghubungi petugas engine hall untuk menyesuaikan tekanannya. Tekanan terendah terjadi pada injector cooling pressure, tekanannya memang harus dijaga sampai serendah rendahnya agar injector dapat bekerja dengan optimal dan pembakaran tetap normal. Secara keseluruhan tekanan yang terjadi pada masing-masing komponen tidak menunjukkan perubahan yang signifikan, jadi tekanan tersebut masih stabil sehingga mesin dapat bekerja dengan baik. 


\subsection{Analisa efek temperatur terhadap komponen mesin}

Gambar 7 menunjukkan nilai temperatur rata-rata dari masing-masing komponen mesin. Temperatur tertinggi terjadi pada fuel temperature karena bahan bakar memang membutuhkan temperatur yang tinggi agar pembakaran terjadi secara cepat dan mudah terbakar, berbeda dengan LT temperatur diketahui memiliki temperatur terendah, tetapi temperatur rendah ini dibutuhkan agar oli mesin tetap terjaga supaya mesin tidak mati. Jika temperatur oli mesin melebihi standar dapat menyebabkan trip pada mesin yaitu mati secara otomatis.

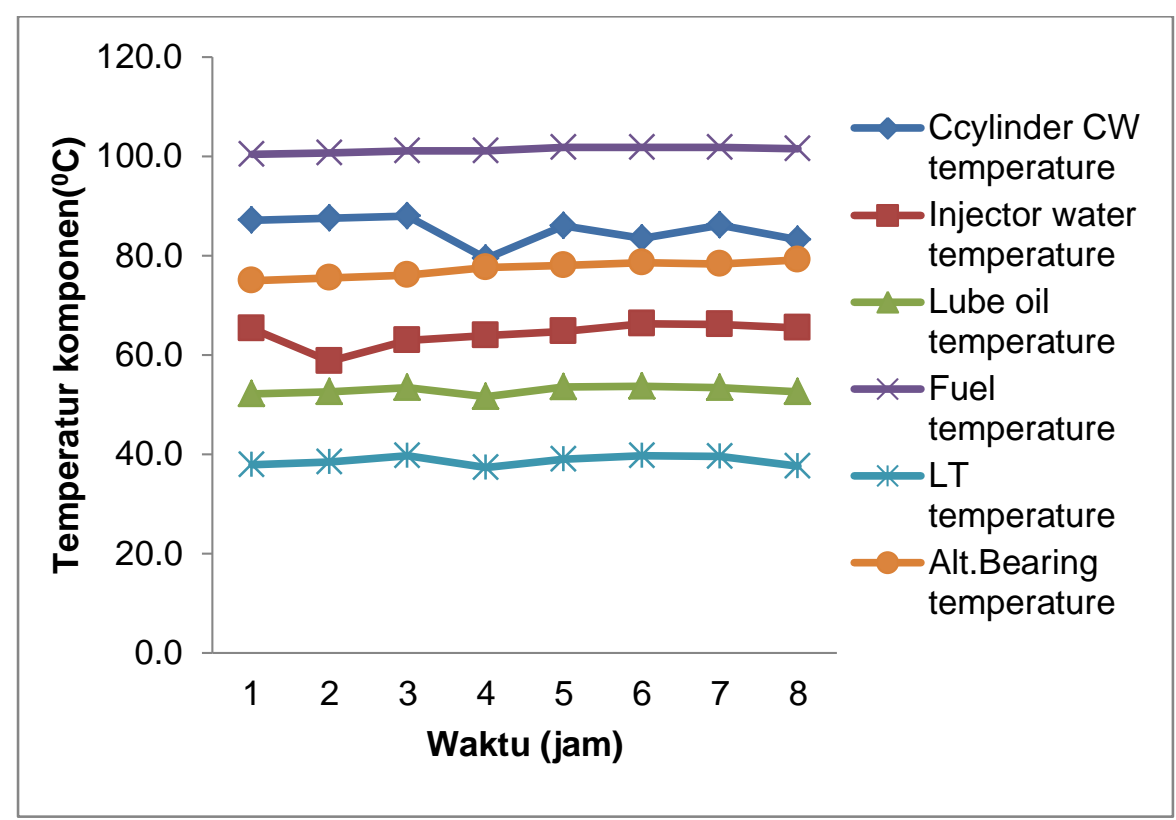

Gambar 7. Efek temperatur terhadap komponen mesin diesel Sulzer Type 16 ZAV 40S

\section{SIMPULAN}

Studi ini dilakukan berdasarkan studi kasus di PLTD sektor Pringgabaya. Hasil penelitian yang dilakukan menunjukkan bahwa getaran dan kebisingan pada mesin diesel di pembangkit listrik dapat menyebabkan efek yang kurang baik bagi kesehatan para pekerja, akan tetapi getaran mesin tidak mempengaruhi sistem kerja pada mesin, parameter yang mempengaruhi kinerja mesin yaitu temperatur, tekanan, bahan bakar, dan udara, jika salah satu dari parameter tersebut bermasalah maka mesin akan mengalami trip (mati secara otomatis). Parameter yang paling sering mengalami masalah adalah parameter temperatur, yaitu temperatur pada silinder sisi $\mathrm{A}$ dan $\mathrm{B}$, dengan temperatur rata-rata bisa mencapai $452^{\circ} \mathrm{C}$ dan temperatur terendah mencapai $423^{\circ} \mathrm{C}$, yang boleh jadi dikarenakan kesalahan saat pembakaran dan lamanya silinder beroperasi, dan umur material dari silinder sehingga terjadi kebocoran dan dapat mempengaruhi gas buang yang keluar.

\section{DAFTAR PUSTAKA}

[1] R. Sadiana, "Analisis Respon Sistem Getaran Pada Mesin Torak," J. Imiah Tek. Mesin, vol. 4, no. 2, pp. 41-46, 2016.

[2] G. D. Laksono, "Analisa getaran ruang kamar mesin pada kapal penyeberangan ketapang-gilimanuk, KMP. Dharma Rucitra,” Skripsi, p. 2016, 2016.

[3] M. Kurnia, M. Isya, and M. Zaki, “Tingkat Kebisingan Yang Dihasilkan Dari Aktivitas Transportasi (Studi Kasus Pada Sebagian Ruas Jalan: Manek Roo, Sisingamangaraja Dan Gajah Mada Meulaboh)," J. Arsip Rekayasa Sipil dan Perenc., vol. 1, no. 2, pp. 19, 2018, doi: 10.24815/jarsp.v1i2.10936. 
[4] M. Nasution, "Ambang Batas Kebisingan Lingkungan Kerja Agar Tetap Sehat Dan Semangat Dalam Bekerja,” Bul. Utama Tek., vol. 15, no. 1, pp. 87-90, 2019.

[5] W. Waspodo, B. Prayogo, and E. Sarwono, "Analisa Performa Mesin Diesel Sulzer Zav 40S Menggunakan Bahan Bakar Mfo Dan Hsd Di Pltd Sungai Raya Pt. Pln (Persero)," Suara Tek. J. Ilm., vol. 9, no. 1, pp. 13-19, 2018, doi: 10.29406/stek.v9i1.1528.

[6] S. Setiawan, "Analisa pengaruh temperatur udara masuk terhadap tekanan dan temperatur gas buang pada PLTD Pulo Panjang Banten," vol. 5, no. 2, pp. 71-76, 2005.

[7] S. E. S. Didit Sumardianto, "Analisa Penyebab Terjadinya Keausan Pada Crankpin Bearing Mesin Diesel Hanshin Model Lh36L," E-journal Widya Eksakta, vol. 1, no. 1, pp. 70-75, 2018.

[8] U. S. Dharma, E. Nugroho, and M. Fatkuahman, "Analisa Kinerja Mesin Diesel Berbahan Bakar," J. Tek. Mesin Univ. Muhammadiyah Metro, vol. 7, no. 1, 2018.

[9] I. I. M. Murni, "Pengaruh Pemakaian Alat Pemanas Bahan Bakar Terhadap Pemakaian Bahan Bakar Dan Emisi Gas Buang Motor Diesel Mitsubishi Model 4D34-2a17," Traksi, vol. 16, no. 2, pp. 66-74, 2016. 